\title{
Semantics of Musical Text as a Key Condition for Development of Secondary Musical Personality
}

\author{
Irina $V$. Cheremisova ${ }^{1, *}$ \\ ${ }^{1}$ Academy of the FPS of Russia, 390000, Ryazan, Russia
}

\begin{abstract}
From the standpoint of the aesthetic and semiotic approach music is understood as a complex psychosemantic text. Theoretical analysis of studies of the psychological connection between music and speech allowed to develop the concept of secondary musical personality as a sort of secondary linguistic personality. The author has developed a musical-semantic pattern of development of secondary musical personality in the educational process. This theoretical pattern is a system of interrelated conditions and factors of development of secondary musical personality. The author determines complexity, polysemy and semantic diversity of the musical text as the key condition. The author attaches special importance to forming potentials of classical music masterpieces in the musical-semantic pattern. The author identifies the artistic, spiritual and ethical levels of music as the main criteria of the musical masterpiece.
\end{abstract}

\section{Introduction}

Theoretical analysis of scientific, scientific and methodical literature and observation of the processes taking place in writing music, mass music education allowed us to notice main contradictions. These contradictions relate to the entire system of psychological support of the creative development of the personality by means of musical art in the educational process.

The first and most important contradiction concerns the need of the person for high-quality musical material and the insufficient supply of such material in the process of mass musical education.

The second contradiction is of methodological importance. On the one hand, it is generally recognized that music education creates the foundation for the development of musical talent, creativity, self-realization in culture and self-improvement, self-education and versatile, harmonious development of the personality on the whole. At the same time, in the domestic psychological and pedagogical science, there is a lack of research of psychological support of the integral affective and cognitive development of a creative personality in his/her musical activity. That raises the issue of psychological support of musical and creative development of the personality in the process of mass music education.

\section{Materials and methods}

\subsection{The Specificity of the Musical Language}

On the basis of theoretical analysis of studies on secondary linguistic personality, we have developed the concept and described the structure of secondary musical personality, we identified psychological conditions and levels of development and determined the content of musical communicative competence. In our study, we base ourselves on the ideas of psychological connection between music and speech, considering music as a special system of relations. The elements of this system are man, the world and the semiotic complex, "the musical language", mediating their interaction [1].

In contrast to language, music has the advantage of direct experience of the essence of human existence [2]. Meanings form the world of the ideal being, that is, the spiritual culture itself.

Cultural meanings, emotional experiences and personalized meaning are embodied in the musical language. In her study, A. V. Toropova presents archetypes that define the process of musical creativity, imagination, inspiration, understanding, meaning formation in art. The recognition process has two directions. The first direction is directed to the musical content, its expressive language of anthropological meanings and emotional experiences. The other direction refers to the individual psychosemantics of musical consciousness. This direction allows the subject to read personalized and common to all mankind meanings of musical experiences, decipher cultural meanings and move forward in his/her musical development [3].

From the standpoint of the aesthetic and semiotic

\footnotetext{
* Corresponding author: irinarusa@inbox.ru
} 
approach, axiological and moral orientations in the structure of secondary musical personality are the determining factor of the development.

\subsection{Cognition in Musical Activity}

Any musical activity (composing, performing or appreciation) is a conscious activity $[4,5,6]$. We shall note that musical activity is a special kind of cognitive activity. This cognitive activity is characterized by cognition in sensory images transmitted through the image.

In science, it is a conceptual apparatus. In art, it is an apparatus of figurative sensual forms and of emotional and imaginative ideas. The specificity of aesthetic activity is not only in cognition at the level of sensory images, that in this case become symbols [1]. Music, as one of the results of human cultural activity and an artificial environment created by people for thousands of years, produces its own specific symbols.

In axiological terms, the perception of musical being is directly related to the emotional perception of the world around [7]. However, the task of musical activity is not reduced to involving a person in the world of emotions or to conveying them. The task of this activity is revealing personalized meaning and this is an act of the highest degree of emotional tension [4].

\subsection{Music as a Complex Psychosemantic Text}

In the XX century, there are many works devoted to semiotic, semantic and general aesthetic problems of musicology. The theory of musical text was the subject of the works by M. G. Aranovsky [8], A.R. Rafikova [9]; the theory of musical language is presented in the studies of E. V. Nazaikinsky [10], G. R. Taraeva [11].

In our opinion, it is reasonable to refer to the semiotic approach to education [12, 13, 14]. For us, semiotic systems in pedagogy are not a means of information coding and decoding but a means of socialization and education. The subject of education semiotics is the interrelation of pedagogical activity with any systems of signs. From the standpoint of the semiotic approach musical art is understood as a complex psychosemantic text filled with common to all mankind (national culture, style of the era, composer) and personalized meanings.

In the research of A. R. Rafikova the musical text is considered (in the narrow sense) as a musical notation of any finished musical work. The musical text (extremely broad definition) is also considered as a field of meanings embodied in all existing systems of signs, codes and notations of different semiotic levels. In the process of acquiring and recognizing meanings of different levels, a person's creative abilities are developing. That is due to the polysemy and semantic diversity of the musical text. [9].

Music as an art form is polymodal by nature and contains "associational semantic fields" $[15,16,17]$. On the one hand, the potential of music is conditioned by the specifics of the organization of the musical text (complexity, diversity of content, activity and directness of emotional and associational influence). On the other hand, the potential of music is conditioned by the peculiarities of musical perception. These features include: personalized and subjective musical perception, associativity, the interaction of various modalities (acoustic analysis, visualization, kinesthetic reactions, unconscious intoning), the act of co-creation in the process of a musical work perception, etc.

O. E. Kamynina presents the following conclusions important for our study: the processes associated with musical perception are dynamic creative processes of cognition of existential experience but not scanning of acoustic reality. [15] Music, due to its polymodal nature, affects a person comprehensively. Such exposure involves complex emotional and associative response, which depends on the content of the musical text, age and emotional experience of the person.

\subsection{Symbolism in Music}

In the context of our study, scientific works aimed at identifying the specific meaning of the multifaceted musical symbol, the role of symbols in music and the process of symbolization in it are of great interest.

The musical language is a special system of signs (symbols), as it can neither be categorically considered among artificial languages nor natural ones. That allows us to see in the musical language a communicative system that has specific content and the ability to display the world in people's minds through musical images [1].

The concept of T. V. Lazutina's research is defined by the understanding of music, its language as symbolism, determined by the cultural and historical context [18].

The work by A. V. Toropova is of great interest to our study. In it, she pays special attention to symbolization in music, archetypes of musical consciousness and their interaction [3].

The process of symbolization in music is based on the preservation of traditions, melodic and harmonic forms, standardized rhythm formulas in the rhythmic organization of music [3].

The musical symbol functions at the following levels of the system of expressive means of the musical language: pitch (melody, harmony, tune, timbre, register, key); rhythmic (rhythmic patterns); compositional (means of creating a composition); performing (agogics, articulation, features, performing intonation).

The study of the musical symbol also caused the need to refer to the works on musical aesthetics by S. Langer, V. N. Kholopova and the works on musical psychology by E. V. Nazaikinsky [10, 19, 20]

In this regard, it is reasonable to pay attention to the category of art axiology, the "masterpiece". 


\subsection{Masterpiece as a Work of Art and Aesthetic maximum}

The main approaches to the problem of the masterpiece are reflected in the philosophical and aesthetic concepts of Western thinkers [21, 22].

The problem of the essence of art and the perfect in art is studied by Russian philosophers [23, 24].

G. V. Ivanchenko considers the problem of the masterpiece in the socio-cultural and psychological aspects of aesthetic perception [25]. On the material of experimental studies of aesthetic perception, the author analyzes the "implicit concepts" of the masterpiece.

The philosophical and aesthetic approach seems appropriate. It is supposed to consider the masterpiece as a product of aesthetic and artistic maximum, as "aesthetic event". The structure of the masterpiece as a work of art is three-layered and includes external, internal forms and an artistic object defined by the axiological "event of being". The masterpiece differs from works of a different level of aesthetic and artistic quality by the following main criteria: the existential value of authenticity, artistic excellence and endless actualization of the semantic intention within the spectator's perception $[26,27,28]$.

Thus, in our understanding, the masterpiece of musical art is a unique, unsurpassed work of the composer, who is a carrier of highly spiritual cultural values, it can be considered as an ideal that stimulates harmonious personal and social development.

The main criteria of the musical masterpiece are: the artistic level of music, the spiritual and ethical level of music.

Musical works, that are usually attributed to classical music, comply with these criteria.

\subsection{Musical-Semantic Pattern of Secondary Musical Personality Development}

On the results of the theoretical analysis, a musicalsemantic pattern of secondary musical personality development was made [29]. In this theoretical pattern, musical art is considered as a synthesis of its objective forms and subjective meanings. Music, musical culture, music education is a repository of experiences that are significant for humanity and concluded in the form of musical meanings [29, 30, 31, 32].

In the centre of the musical-semantic pattern, there is a unique subject of inculturation and socialization secondary musical personality. All the components of the musical-semantic pattern are interrelated and interdependent [33].

In accordance with the theoretical conceptual pattern, we have developed and subsequently implemented a programme of psychological support for the creative development of the personality by means of musical art "Up the Steps of Music to the Heights of Creativity."

Secondary musical personality is the result of musical education. This is a musically and creatively active subject that is able to learn, assess and transform the surrounding reality and his/her own musical and creative environment, to participate in communication by means of musical art in the process of musical activity. The level of development of the person's musical consciousness and the level of musicallinguistic, musical-speech competence depend on the level of development of the properties and abilities that make up the psychological structure of secondary musical personality in the totality of the components [29].

\subsubsection{Assessment in the Musical-Semantic Pattern}

For the assessment of musical and creative development of personality in the musical-semantic pattern, there is a comprehensive technique of studying musical and creative development of personality, including observation, interviews, surveys, tests, analysis of products of students' creative activity.

\subsubsection{Principles and Methods of Assessment of Musical and Creative Development of Personality}

The following methods were used to assess musical and creative development in adolescence and at preadult age [34].

Test "Definition of Creativity" by H. Sievert, Test "Circles" by N. M. Peysakhov, Methods of Psychosemiotic Analysis of the Text by I. M. Kyshtymova [35], Methods of Expert Evaluation "Questionnaire of Creativity" by D. Johnson, Test "Assessment of artistic and aesthetic needs" by V. S. Avanesov, Methods on "Level of Artistic Perception" by V. A. Vedenkina, Methods on "Self-Assessment of Personality" by B. A. Sosnowski in the modification by O. I. Motkov, Questionnaire "Index of Schoolchildren's Education" for grades 7-11, Proprietary Methodology "Green Spots" [34] for studying the level of imagination development, Proprietary Test "Determining the Level of Musicality (DLM)" [34].

A significant part of the assessment of the level of secondary musical personality development in our conceptual pattern is the analysis of works, that are musical impressions, reports, that are self-observation, products of creative activity made under the impression of listened music, as a result of musical and creative activity. We have developed several schemes of analysis of these works [29]. .

In addition, an important principle of the assessment of musical and creative development of personality is the prolonged diagnosis of creativity under natural conditions of life and on the basis of the analysis of the subjects' real creative achievements [29].

This approach to psychological assessment of musical and creative development of personality is tested within the program of psychological support "Up the Steps of the Music to the Heights of Creativity" and helped to obtain trustworthy results and reasonable conclusions. 


\section{The results of the study}

\subsection{Development of secondary musical personality at different levels of education}

The experimental study was conducted on the basis of educational institutions of Nizhny Novgorod and the Nizhny Novgorod Region, the Vladimir Region, the Volgograd Region. The study involved: students of secondary school (grade 7-10) - 726 people (among them 300 people from grade 7-8, 426 people from grade 9-10); teachers from educational institutions - teachers from secondary schools - 130 people, teachers from music schools -63 people.

To study the musical and creative level of the subjects it was necessary to determine the criteria and indicators of productivity of musicality, musical and creative development at different levels of education. Under the productive musical and creative development of personality we understand the development of secondary musical personality in the educational process in the totality of all the components: music and cognitive, motivational, emotional, communicative, activity, spiritual and ethical.

The results of the final assessment indicate significant positive dynamics in the cognitive and personal development of the experimental groups of students $(p<0.01)$. The experience of musical and creative performing of the forming programme participants contributed to the development of their interest in musical activity, development of musicality and their general creative abilities. In addition, participation in the programme contributed to increasing the students' need for self-development, the formation of positive self-esteem, the development of the capacity for reflection $(\mathrm{p}<0.05)$. Watching the students, and talking to their parents and teachers, we became convinced of the significant positive dynamics in the musical and creative development of adolescents and high school students participants of the experimental groups.

\section{Discussion and conclusion}

Defining musical activity as a kind of aesthetic activity, we define the product of this activity. From this point of view, the product of musical activity is not revealing, expressing and transferring the sense but the personalized meaning of phenomena. Art, musical art is the only activity that is able to realize the task of revealing, expressing and communicating the personalized meaning of reality. [4].

The realization of personalized meaning is possible only by means of culture, which is semiotic [14]. The level of human's mastering "the means of culture" determines the adequacy of his expression of personalized meaning; it determines the poossible variability of combinations of the used sign system elements [35].

Thinking of the reasons for the special efficacy of art A. N. Leontiev notes that the true and powerful regulator is neither sense nor understanding. You may understand, use and know the sense, but it will not be enough to regulate and manage life processes. The strongest regulator is what A. N. Leontiev defined by the term "personalized meaning". A. N. Leontiev states that art includes and conveys meaning, the strongest thing in the regulation of activity. Therefore, according to A. N. Leontiev, art does not inform, it prompts people [4].

Creating on the basis of reality an artistic image in the human consciousness, art elevates the private (subjective) form of existence to an abstract level of universal meaning.

The main position of the aesthetic-semiotic approach is that the high artistic level and the deep spiritual and ethical content of the musical masterpiece contributes to the development of axiological and moral orientations of the person [36]. These orientations are the determining factor in the development of secondary musical personality.

\section{References}

1. T.A. Ryzhkova-Dudonova, Music in the context of the cultural picture of the world, $\mathrm{PhD}$ Culturology sci. diss. (Moscow, 2005)

2. P.P. Kushmina, Language and Music as Semantic Sound Forms of Culture, PhD Philos. sci. diss. ( Kazan, 2004)

3. A.V. Toropova, The phenomenon of musical consciousness: the methodology of research and development, Dr. ped. sci. Diss. (Moscow, 2009)

4. A.N. Leontiev, Philosophy of psychology, (Moscow University Press, Moscow, 1994)

5. L.P. Novitskaya, Psychological Magazine, Effect of different music styles on the mental state of a human being, 6, 79-85 (1984)

6. M.A. Rohrmeier, S. Koelsch, Int. J. Psychophysiol., Predictive information processing in music cognition. A critical review, 83, 164-175 (2012)

7. L.L. Balkwill, W.F. Thompson, Music Percept., $A$ cross-cultural investigation of the perception of emotion in music: Psychophysical and cultural cues, 17, 43-64 (1999)

8. M.G. Aranovsky, Musical text: structure and properties, (Composer, Moscow, 1998)

9. A.R. Rafikova, Semantics musical text: philosophical analysis, $\mathrm{PhD}$ Philosophy sci. diss. (Chuvashskiy State University, Cheboksary, Russia, 2006)

10. E.V. Nazaikinsky, On the psychology of musical perception (Music, Moscow,1972)

11. G.R. Taraeva, Semantics of the musical language: conventions, traditions, interpretations (Art-transit, Moscow, 2012)

12. R. Bart, Selected works: Semiotics: Poetics (Progress, Moscow, 1989)

13. C. Levi-Strauss, Structural anthropology (EksmoPress., Moscow,2001)

14. Y. Lotman, Universe Of The Mind (Art, St. Petersburg, 2000) 
15. O.E. Kamynina, The Development of polymodal perception in younger students in the process of musical activity, $\mathrm{PhD}$ Psychol. sci. diss (St. Petersburg, 2009)

16. J. McDermott, M. Hauser, Music Percept., The origins of music: Innateness, uniqueness, and evolution, 23 (29-59) 2005

17. M. Muller, L. Hofel, E. Brattico, T. Jacobsen, Aesthetic judgments of music in experts and laypersons - An ERP study, Int. J. Psychophysiol. 76, 40-51 (2010)

18. T.V. Lazutina, Onto-epistemological and Axiological Basics of Music Language, Dr. philosof. sci. diss., (Ural State University, Ekaterinburg, 2009)

19. S. Langer, Philosophy in a new way: the Study of the symbolism of reason, ritual and art (Republic, Moscow, 2000)

20. V.N. Kholopova, The unconscious in the perception of musical content (Mosc. state Conservatory. P.I. Tchaikovsky, 2002)

21. R.Bart, Mythology (Izd-vo im. Sabashnikov, Moscow, 1996)

22. H.-G. Gadamer, Voprosy Filosofii, Game of art $\mathbf{8}$, 164-168 (2006)

23. N.A. Berdyaev, The destiny of man (Republic, Moscow, 1993)

24. N.A. Lossky, The World as the realization of beauty : Fundamentals of aesthetics (Progress-Tradition, Moscow, 1998)

25. G.V. Ivanchenko, Psychology of music perception: approaches, problems, prospects : Approaches, problems, prospects (Sense, Moscow, 2001)

26. E.P. Chensky, Is a Masterpiece as an aesthetic phenomenon, $\mathrm{PhD}$ Philosophy sci. diss. (St. Petersburg, 2007)
27. E. Brattico, M. Pearce, The Neuroaesthetics of Music. Psychology of Aesthetics, Creativity, and the Arts, 7 (1) 48-61 (2013)

28. E. Istók, E. Brattico, T. Jacobsen, K. Krohn, M. Müller, M. Tervaniemi, Musicae Scientiae Aesthetic responses to music: a questionnaire study. 13, 183206 (2009)

29. I.V. Cheremisova, European Journal of Multidisciplinary Studies Music and Development of Creative Personality Within Higher Education Environment. Aesthetic and Semiotic Approach, 4(1), 78-87 (2017)

30. Hannon, E.E., Trainor, L.J., 2007. Music acquisition: effects of enculturation and formal training on development. Trends in Cognitive Sciences. 11, 466472.

31. J. Burton, Leaning In and Through the Arts (Columbia University, N.Y., 2008)

32. V.V. Ryzhov, Personality, creativity, and spirituality (St. Petersburg Christian University Publ., St. Petersburg, 2012)

33. I.V. Cheremisova, Science Journal of Volgograd State University. Philosophy. Sociology and Social Technologies, Secondary musical personality: philosophical and culturological basics of research and development, , 1 (21), 21-32 (2014)

34. I.V. Kurysheva, Psychological conditions of development of creative potential of senior pupils by means of musical art (Nizhegor. Phil. The Institute of business and politics NF UPS, Nizhniy Novgorod, 2008)

35. I.M. Kyshtymova, Psychosemiotics of Creativity (Publishing house of Irkutsk State University, Irkutsk, 2008)

36. I.V. Kurysheva Psychological Basics of Musical and Creative Development of Personality in the Process of Education. Dr. psychol. sci. diss. Nizhniy Novgorod, 438 (2011) 